\title{
Rheological Properties of High Melt Strength Poly(ethylene terephthalate) Formed by Reactive Extrusion
}

\author{
J. S. Forsythe, ${ }^{1}$ K. Cheah, ${ }^{2}$ D. R. Nisbet, ${ }^{1}$ R. K. Gupta, ${ }^{3}$ A. Lau, ${ }^{2}$ A. R. Donovan, ${ }^{2}$ M. S. O'Shea, ${ }^{2}$ \\ G. Moad $^{2}$ \\ ${ }^{1}$ CRC for Polymers, Department of Materials Engineering, Monash University, Victoria 3800, Australia \\ ${ }^{2}$ CRC for Polymers, CSIRO Molecular Science, Clayton South, Victoria 3169, Australia \\ ${ }^{3}$ CRC for Polymers, School of Civil and Chemical Engineering, RMIT University, Melbourne, Victoria 3001, Australia
}

Received 18 June 2005; revised 31 August 2005; accepted 1 September 2005

DOI 10.1002/app.23166

Published online in Wiley InterScience (www.interscience.wiley.com).

\begin{abstract}
A reactive extrusion process was developed improving the rheological properties of PET via the coaddition of a dianhydride and polyol. Specifically, the coaddition of pyromellitic dianhydride (PMDA) with pentaerythritol resulted in a gel-free polyester with superior melt strengths and viscosities compared to the addition of PMDA alone. The enhancement in rheological properties were dependent on the relative amounts of dianhydride and polyol with the
\end{abstract}

resultant polyester structurally stable in the melt. These results are consistent with the formation of a hyperbranched polyester with long chain branches. (C) 2006 Wiley Periodicals, Inc. J Appl Polym Sci 100: 3646-3652, 2006

Key words: reactive extrusion; poly(ethylene terephthalate); PET; chain extension; branching; PMDA; pentaerythritol

\section{INTRODUCTION}

Poly(ethylene terephthalate) (PET) has an inherently poor melt strength and viscosity, which has restricted its use in many applications such as blow-molding and extrusion foaming. Specialty grades of PET are available but are often economically restrictive due to the high costs involved in production, e.g., lengthy solid stating processes are required. Much attention has been focused on using reactive extrusion processes with low molecular weight modifiers such as polyanhydrides and polyepoxides, to induce chain extension and branching of low cost, low IV PET to yield polyesters with enhanced rheological and mechanical properties. ${ }^{1}$

Incarnato et al. $^{2}$ used pyromellitic dianhydride (PMDA) in a reactive extrusion process to increase the molecular weight of low IV (0.48 dL/g) PET. Increased dynamic viscosities at low frequencies, higher melt strengths, and more pronounced shear thinning were observed and attributed to a combination of long chain branching and a broadening of the molecular weight distribution. However, the contributions from the two mechanisms could not be elucidated. In a later study, the same authors ${ }^{3}$ investigated PMDA-modified PET for use in film blowing applications and

\footnotetext{
Correspondence to: J. S. Forsythe (john.forsythe@eng. monash.edu.au).

Contract grant sponsor: CRC for Polymers.
}

Journal of Applied Polymer Science, Vol. 100, 3646-3652 (2006) (C) 2006 Wiley Periodicals, Inc. found increased bubble stability with increasing PMDA concentrations. However, at high concentrations of PMDA $(0.75 \mathrm{w} / \mathrm{w} \%)$, there was increased bubble stability but a drop in the draw up ratio which was attributed to higher yields of long chain branching and some crosslinking. Awaja et al. ${ }^{4}$ used PMDA in a reactive extrusion process to increase the viscosity of post consumer PET. End-group analyses showed a linear decrease in the hydroxyl content with increasing PMDA concentration and residence time for a given PMDA concentration. However, crosslinking and gel formation caused instability in the extruder at PMDA concentrations above 0.3 wt $\%$. Khemani ${ }^{5}$ found the polydispersity, $M_{z} / M_{n}$ of modified PET $(0.2$ wt $\%$ PMDA) to significantly increase compared to the unmodified PET in a reactive extrusion process. Xanthos et al. ${ }^{6}$ compared the effectiveness of some low molecular weight, multifunctional anhydride, and epoxy compounds in a reactive extrusion process targeted at foaming applications. Improvements in the rheological properties such as die swell, melt strength, and melt flow index (MFI) were related to molecular weight increases and broadening of the molecular weight distribution. Some of the epoxide chain extenders produced appreciable level of gels indicating that crosslinking was occurring in these systems.

Other low molecular weight modifiers have been employed, which exploit the reactivity of the hydroxy and carboxyl PET chain ends. These include multifunctional epoxides, ${ }^{6-9}$ tertiary phosphites ${ }^{10}$ and cyclic imino ethers. ${ }^{11}$ However, these processes have met with mixed success for one or more of the following 
reasons: uncontrollable crosslinking or gel formation $^{6,12}$; only existing end groups are available for reaction; end capping of reactive end groups at high additive concentrations ${ }^{13}$; limited control over the length of branches; and shear induced degradation during reactive extrusion. ${ }^{14}$

Previous reactive extrusion experiments carried out by some of the authors ${ }^{14}$ have shown that many of the limitations can be overcome by the coaddition of a polyanhydride, such as PMDA with a lesser amount of a polyhydric alcohol such as pentaerythritol. Through careful control of the ratios of the components, marked improvements in the melt viscosity, melt strength, and molecular weight were observed when PMDA and pentaerythritol were added in combination. Compared to addition of PMDA alone, coaddition also resulted in lower extruder torque values, die pressures, melt temperatures, and produced an extrudate with lower levels of degradation as evidenced by substantially less discoloration. O'Shea and coworkers proposed that the polyhydric alcohol underwent alcoholysis to produce a branched polyester with the added feature of substantially increasing the concentration of hydroxy end groups available for coupling and branching reactions known to occur with dianhydrides. The dianhydride may also act to scavenge water, which is a byproduct of alcoholysis, thereby limiting further hydrolysis reactions and decreases in molecular weight. Therefore, by careful adjustment of the dianhydride and polyhydric alcohol ratios, control over the level of branching could be achieved.

The present study investigates the rheological properties of PET modified in a reactive extrusion process by the coaddition of PMDA and pentaerythritol at different compositions.

\section{EXPERIMENTAL}

\section{Materials}

Bottle grade PET (Bakrie Kasai BK3180, 3\% isophthalic acid comonomer) and post consumer PET (Visy, Australia) with nominal intrinsic viscosities IV $=0.82$ and 0.73 respectively, were used. Pyromellitic dianhydride (PMDA, Plastral Fidene) and pentaerythritol (Sigma-Aldrich, Australia) were obtained as powders and dried in a vacuum oven at $150^{\circ} \mathrm{C}$ under reduced pressure before use.

\section{Processing}

All reactive extrusion experiments were performed using a Japan Steel Works, $30 \mathrm{~mm}$ diameter twin screw extruder (JSW TEX30) of L/D ratio 42 operating in a corotating mode at a screw speed of $95 \mathrm{rpm}$ and utilizing a combination of dispersive and distributive mixing elements. A flat temperature profile of $270^{\circ} \mathrm{C}$ was used along the barrel. PET pellets were dried in a hopper drier overnight at $120^{\circ} \mathrm{C}$ to a moisture level below $50 \mathrm{ppm}$ and were directly fed to a gravimetric feeder, which was also maintained under dehumidified conditions to prevent exposure to atmospheric moisture. Moisture levels were analyzed using a Texas Moisture Analyzer. The PMDA and pentaerythritol were dry blended with dried PET powder just prior to addition and fed via a K-Tron Feeder which was kept under a nitrogen blanket. The extruded strand was cooled in a water bath and pelletized.

All extruded polyester samples were analyzed for gels by Soxhlet extraction with tetrachloroethane as solvent for $24 \mathrm{~h}$.

\section{Rheological measurements}

In-line rheological measurements (steady shear viscosity and MFI measurements at $285^{\circ} \mathrm{C}$ ) were obtained using a Porpoise P3 rheometer (dual die system) attached via a gear pump at the end of the extruder. $\mathrm{L} / \mathrm{D}$ ratios of 20.0 and 3.8 were employed using a Bagley correction. In-line melt strength measurements were obtained at $285^{\circ} \mathrm{C}$ using a Gottfert "Rheotens" melt strength tester positioned $210 \mathrm{~mm}$ underneath the in-line rheometer having a capillary die diameter of $2 \mathrm{~mm}$. The resulting melt strand was drawn by rotating rollers with a constant acceleration of $1.2 \mathrm{~cm} / \mathrm{s}^{2}$.

Off-line dynamic shear storage modulus measurements were performed using a Rheometrics ARES rheometer with parallel-plate geometry at $285^{\circ} \mathrm{C}$ under dry nitrogen. Off-line MFI measurements were performed according to ASTM D 1238, using a Tinius Olsen Model MP 993 Extrusion Plastometer (Melt Indexer). The experiment was performed with a $2060 \mathrm{~g}$ mass at $285^{\circ} \mathrm{C}$, allowing a melt time of $180 \mathrm{~s}$ and a cut time of $300 \mathrm{~s}$.

\section{End group determination by titration}

Acid end-group analyses were carried out at Leading Synthetics (Campbellfield, Australia). Samples were dried and dissolved in 0 -cresol at $130^{\circ} \mathrm{C}$ for $\sim 30 \mathrm{~min}$. Solutions were titrated with $0.05 \mathrm{~N}$ ethanol $\mathrm{KOH}$ solution. The end point of the titration was determined using an automatic potentiometric titration unit. All samples were run in duplicate.

\section{End group determination by derivatization and ${ }^{\mathrm{H}} \mathrm{HMR}$}

The $400 \mathrm{MHz}{ }^{1} \mathrm{H}$ NMR spectra were obtained with a Bruker Avance AV400 spectrometer. A sample of PET (15 mg) was first rendered amorphous by rapid thermal quenching. The sample was placed in an open aluminum sample pan and heated to $270^{\circ} \mathrm{C}$ at $10^{\circ} / \mathrm{min}$ 


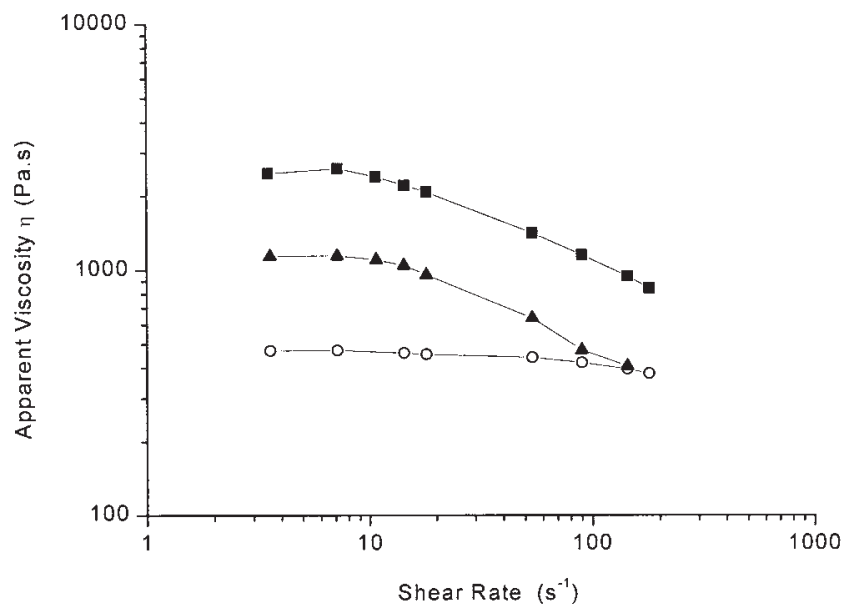

Figure 1 In-line steady shear measurements of PMDA-

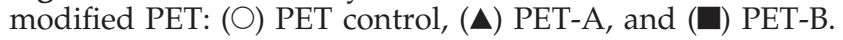

in a DSC furnace (Mettler Toledo DSC821 equipped with a TSO801RO sample robot), then removed from the furnace and allowed to cool to ambient temperature. The entire operation was carried out under nitrogen. The amorphous material was then powdered and dissolved in tetrachloroethane-1,2- $d_{2}\left(\mathrm{CD}_{2} \mathrm{Cl}_{2}\right)(0.5$ $\mathrm{mL})$ at $140^{\circ} \mathrm{C}$. After dissolution the mixture was transferred to an NMR tube, an excess of trichloroacetyl isocyanate (TAI; $4 \mu \mathrm{L}, 6.3 \mathrm{mg}, 3.36 \times 10^{-2} \mathrm{mmol}$ ) was added and the ${ }^{1} \mathrm{H}$ NMR spectrum recorded for 1024 scans. ${ }^{1} \mathrm{H}$ NMR: $\delta_{\mathrm{H}}\left(\mathrm{CD}_{2} \mathrm{Cl}_{2}, 400 \mathrm{MHz}\right), 10.25(1 \mathrm{H}, \mathrm{s}$, end-group $\left.-\mathrm{C}(\mathrm{O})-\mathrm{O}-\mathrm{C}(\mathrm{O})-\mathrm{NH}-\mathrm{C}(\mathrm{O}) \mathrm{CCl}_{3}\right), 8.55$ $\left(1 \mathrm{H}\right.$, s, end-group $\left.-\mathrm{O}-\mathrm{C}(\mathrm{O})-\mathrm{NH}-\mathrm{C}(\mathrm{O}) \mathrm{CCl}_{3}\right), 8.10$
$(4 \mathrm{H}, \mathrm{s}, \mathrm{PET}$ atom $\mathrm{H}), 4.70\left(4 \mathrm{H}, \mathrm{s}, \mathrm{PET} \mathrm{OCH}_{2}\right)$ other signals at $\delta_{\mathrm{H}} 8.70$ and on the fringe of the PET aromatics are due to isophthalate arom $\mathrm{H}$ (see Fig. 6). Integration shows that the PET BK3180 contains 2.5 $\mathrm{mol} \%$ isophthalate units with respect to terephthalate units.

\section{RESULTS AND DISCUSSION}

All modified polyesters were free of gels indicating minimal crosslinking reactions (no gel fractions were obtained after soxhlet extraction). Figure 1 shows the effect of PMDA addition on the steady shear viscosity of bottle grade PET. The unmodified PET control exhibited Newtownian flow behavior typical of a linear polymer with a relatively narrow molecular weight distribution. ${ }^{15}$ The modified polyesters (PET-A and PET-B) became increasingly viscous at increased doses of PMDA with higher viscosities at low shear rates as well as significant drops in the MF1 (Table I). The addition of PMDA also increased the melt strength up to $12 \mathrm{cN}$ for PET-B (Table I). Xanthos et al. ${ }^{6}$ obtained a similar melt strength of $10.5 \mathrm{cN}$ using PMDA at 0.7 phr corresponding to a $50 \%$ excess of the hydroxyl end groups. The viscosity at low shear rates (nominally 4 $\mathrm{s}^{-1}$ ) correlated with the ranking of the MFIs for all materials (Table I). Increased shear sensitivity, particularly at the higher shear rates, were observed for the PMDA modified polyesters. The extrusion process at $0.20 \mathrm{wt} \%$ PMDA (PET-B) represented the upper limit of PMDA addition under our experimental conditions. Attempts to increase the PMDA concentration to 0.25

TABLE I

In-Line Rheological Measurements Conducted at $285^{\circ} \mathrm{C}$ Using Bottle Grade PET $(\mathrm{IV}=0.82)$ and Postconsumer PET $($ PC-PET IV $=0.73)$

\begin{tabular}{|c|c|c|c|c|c|c|}
\hline Material & wt $\%$ PMDA & $\begin{array}{c}\text { Mole ratio } \\
\text { (PMDA/pentaerythritol) }\end{array}$ & $\begin{array}{l}\text { MFI (g/10 min) } \\
\text { in-line }\end{array}$ & $\begin{array}{l}\text { Melt strength } \\
(\mathrm{cN})\end{array}$ & $\begin{array}{l}\text { Aparent viscosity } \\
\text { at } 4 \mathrm{~s}^{-1}(\mathrm{~Pa} \mathrm{~s})\end{array}$ & $\begin{array}{c}{[\mathrm{COOH}]} \\
\text { (titration) } \\
\left(\mathrm{eq} / 10^{6} \mathrm{~g}\right)\end{array}$ \\
\hline Virgin PET & - & - & $19^{a}$ & - & - & 11 \\
\hline PET Control & 0 & - & 22 & $-^{\mathrm{b}}$ & 469 & 34 \\
\hline PET-A & 0.10 & - & 15 & 3 & 1138 & 15 \\
\hline \multirow[t]{2}{*}{ PET-B } & 0.20 & - & $11^{\mathrm{a}}$ & 12 & 2488 & 30 \\
\hline & 0.25 & Viscosity too high to extrude & & & & \\
\hline PET-C & 0.10 & $5: 1$ & 10 & 2 & 1330 & 12 \\
\hline PET-D & 0.20 & $5: 1$ & 4 & 20 & 3834 & 44 \\
\hline PET-E & 0.25 & $5: 1$ & 4 & 23 & 4137 & 28 \\
\hline PET-F & 0.30 & $5: 1$ & 4 & $42^{\mathrm{c}}$ & 4693 & 36 \\
\hline PET-G & 0.10 & $8: 1$ & 10 & 3 & 1456 & 15 \\
\hline PET-H & 0.20 & $8: 1$ & 6 & 8 & 2632 & 35 \\
\hline PET-I & 0.25 & $8: 1$ & 3 & $42^{\mathrm{C}}$ & 5209 & 32 \\
\hline PET-J & 0.30 & $8: 1$ & 4 & $40^{c}$ & 4948 & 40 \\
\hline PC-PET Control & 0 & - & 41 & $-^{\mathrm{b}}$ & 266 & - \\
\hline PC-PET-A & 0.25 & $5: 1$ & 22 & 13 & 883 & - \\
\hline PC-PET-B & 0.30 & $5: 1$ & 12 & 17 & 2546 & - \\
\hline
\end{tabular}

${ }^{a}$ Performed off-line.

${ }^{\mathrm{b}}$ No measurable melt strength.

c Strand crystallized during measurement. 


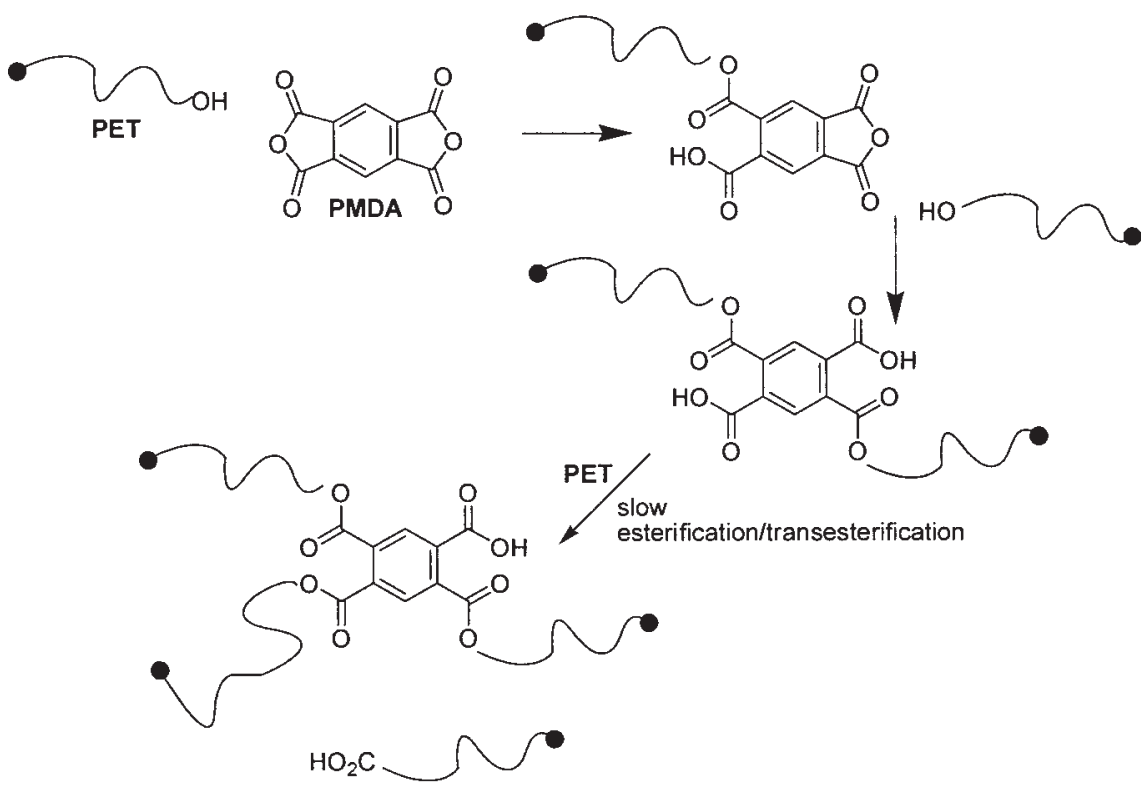

Scheme 1 Chain extension/branching of PET with PMDA ( represents COOH chain ends).

wt $\%$ were unsuccessful due to high viscosities and ultimate seizure of the extruder (data not shown).

The addition of dianhydrides to linear polyesters in the melt has been used extensively to promote chain extension and branching; however, the extent of each mechanism is not entirely understood. Khemani ${ }^{5,16}$ proposed a mechanism involving initial ring opening of the dianhydride on reaction with the polyester hydroxy end groups resulting in chain extension and concomitant formation of pendant carboxylic acid groups. Depending on the concentration of PMDA, a partially branched or crosslinked polyester could be formed by a number of mechanisms including reaction of the newly formed pendant acid groups by esterification or transesterification reactions (Scheme $1)$.

However at the PMDA concentrations used in this study and the relatively short residence time in the extruder, we propose that addition of PMDA alone to PET results predominantly in chain extension reactions between the anhydride groups, and the alcohol end groups resulting in increases in the molecular weight and a broadening of the molecular weight distribution. ${ }^{5}$ This can be justified because, (1) the known higher reactivity of anhydrides as opposed to carboxylic acids, (2) the concentration of hydroxy end groups are in excess to the amount of added anhydride groups, and (3) comparatively slower rates of transesterification and esterification reactions. Some long chain branching is possible but we, nonetheless argue that the predominant process of PMDA under our extrusion conditions is chain extension.

Coaddition of pentaerythritol with PMDA at a molar ratio of $5: 1$ (PMDA : polyol) had a marked effect on the rheological properties of the polyesters (Table I). Pentaerythritol is a tetrafunctional molecule and most likely introduces branches via a series of alcoholysis reactions with ester groups in the polyester. However, the reaction also results in chain scission (Scheme 2) and is therefore not an effective branching agent when used alone in a reactive extrusion process.

At low levels of coaddition (PET-C), there was a significant drop in the MFI compared to when PMDA was added alone (PET-A), however, there was little improvement in the melt strength. This could be attributed to the MFI being more sensitive to increases in viscosity as well as a lack of chain branching at this additive level, i.e., the major process was still chain

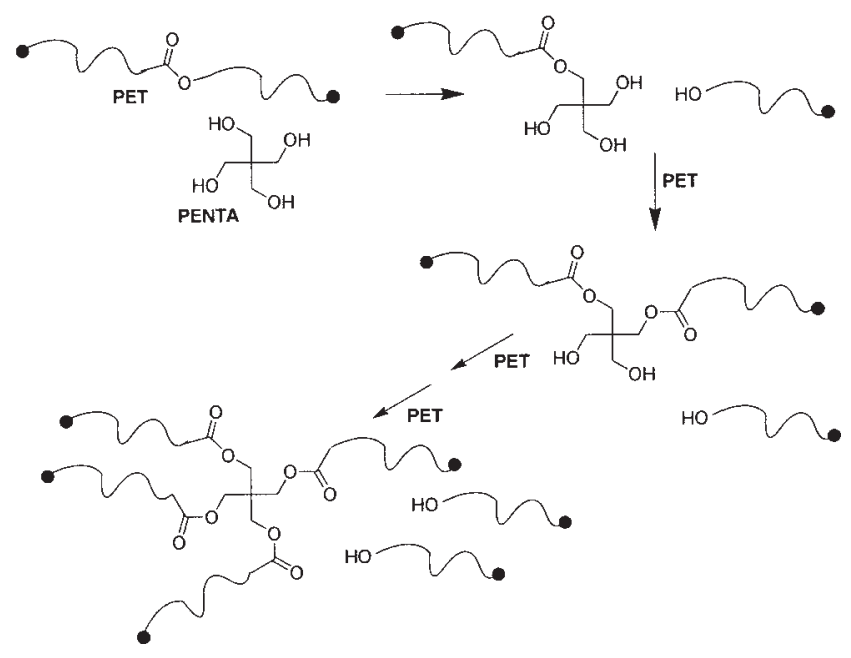

Scheme 2 Alcoholysis of PET with pentaerythritol ( represents $\mathrm{COOH}$ chain ends). 


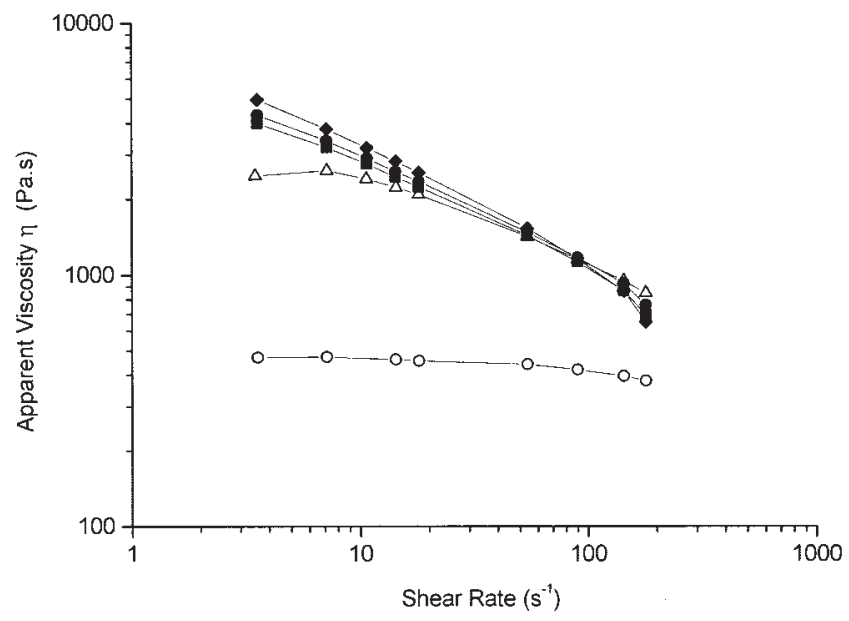

Figure 2 In-line steady shear properties of modified PET. Effect of coaddition of pentaerythritol at a 5:1 mole ratio PMDA:pentaerythitol: (O) PET Control, (ם) PET-D, (๑) PETE, $(\diamond)$ PET-F, and $(\triangle)$ PET-B shown for comparison.

extension. However, at higher concentrations (PET-D, $\mathrm{E}, \mathrm{F})$ there were marked increases in melt strengths. Pentaerythritol also allowed the dose of PMDA to continue past $0.20 \mathrm{wt} \%$ and provided further increases in viscosities at low shear rates and decreases in the MFI (Fig. 2, Table I). Similar behavior was also observed for postconsumer PET, showing that this process can be utilized with polyesters with significantly lower molecular weights and different endgroup compositions (Fig. 3, Table I).

Interestingly, Figure 2 shows that coaddition of pentaerythritol increased the shear sensitivity across the entire shear rate range investigated, whereas PET-B (0.20 wt \% PMDA) only exhibited shear thinning at shear rates higher than $10 \mathrm{~s}^{-1}$. The enhanced shear sensitivity of the polyesters modified by the coaddi-

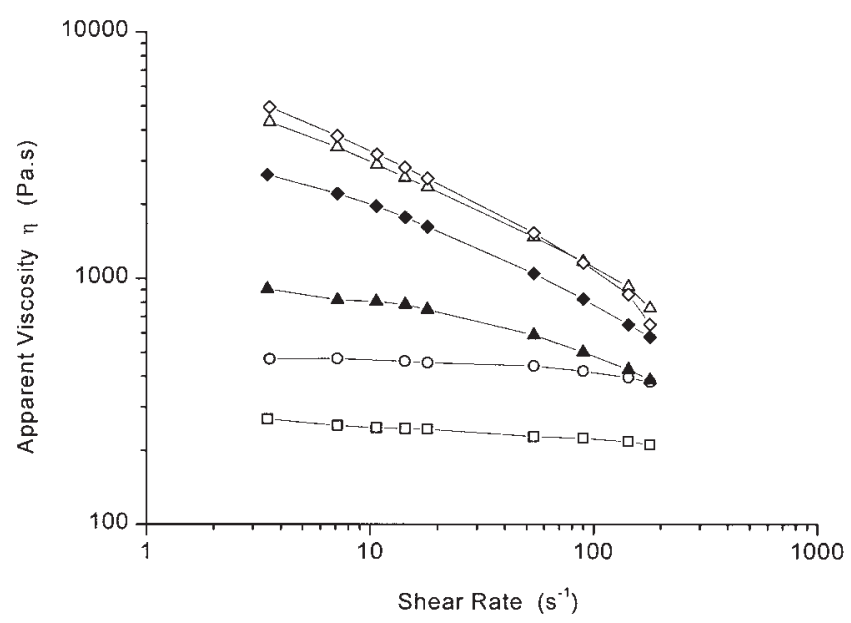

Figure 3 In-line steady shear properties of post consumer

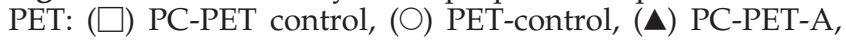
$(\triangle)$ PET-E, $(\diamond)$ PC-PET-B, and $(\diamond)$ PET-F.

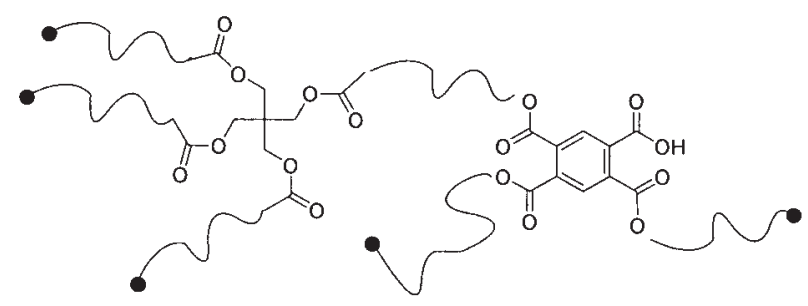

Scheme 3 Structure formed by coaddition of PMDA and pentaerythritol ( represents $\mathrm{COOH}$ chain ends).

tion of PMDA and pentaerythritol (PET-D, E, F) is attributed to increased branching of the polyester. In the polymer melt, the pentaerythritol will cause rapid branching and chain scission of the polyester, while the PMDA will bring about chain extenstion to form a highly branched structure shown in Scheme 3. The PMDA may also act as a dehydrating agent, mopping up water from esterification reactions thereby preventing further chain scission. These reactions would lead to a molecular architecture significantly different to PMDA addition alone. The architecture will be hyperbranched with a shorter distance between branch points.

To further investigate the effects of coaddition, the molar ratio of PMDA to pentaerythritol was deliberately varied. Figure 4 shows the effect of increasing the molar ratio of PMDA to pentaerythritol from 5:1 to 8:1 on the steady shear viscosity. There was no significant difference in the apparent viscosity, except at $0.20 \mathrm{wt}$ $\%$ PMDA (PET-D and PET-H), where the increased amount of pentaerthritol increased the melt viscosity and provided higher melt strengths (Table I). Figure 5 shows differing behavior at 0.20 wt \% PMDA, with PET-H exhibiting extensive drawing (similar to low

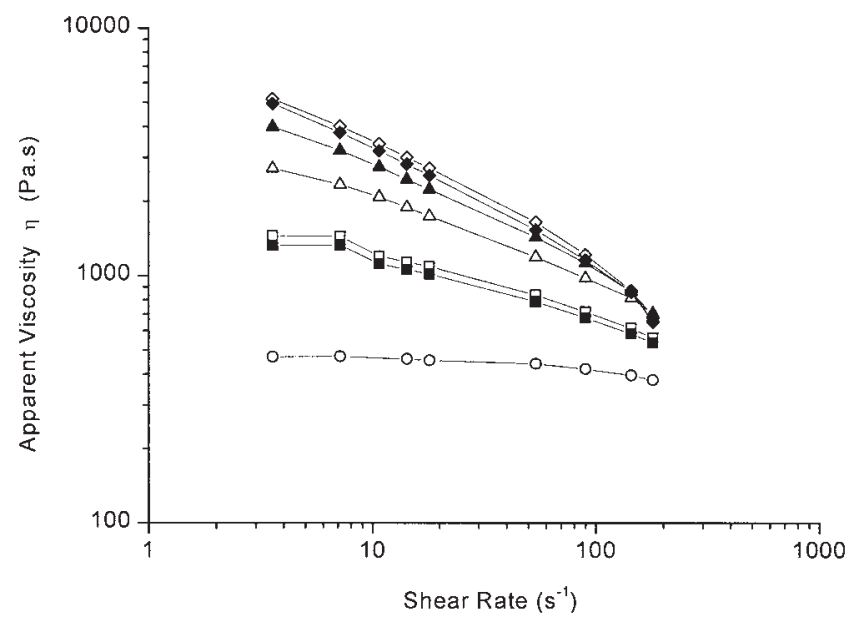

Figure 4 In-line steady shear properties of modified PET: Effect of varying pentaerythritol concentration. (O) PET Control, ( $\square$ ) PET-G, (ם) PET-C, $(\triangle)$ PET-H, $(\Delta)$ PET-D, $(\diamond)$ PET-J, and $(\diamond)$ PET-F. 


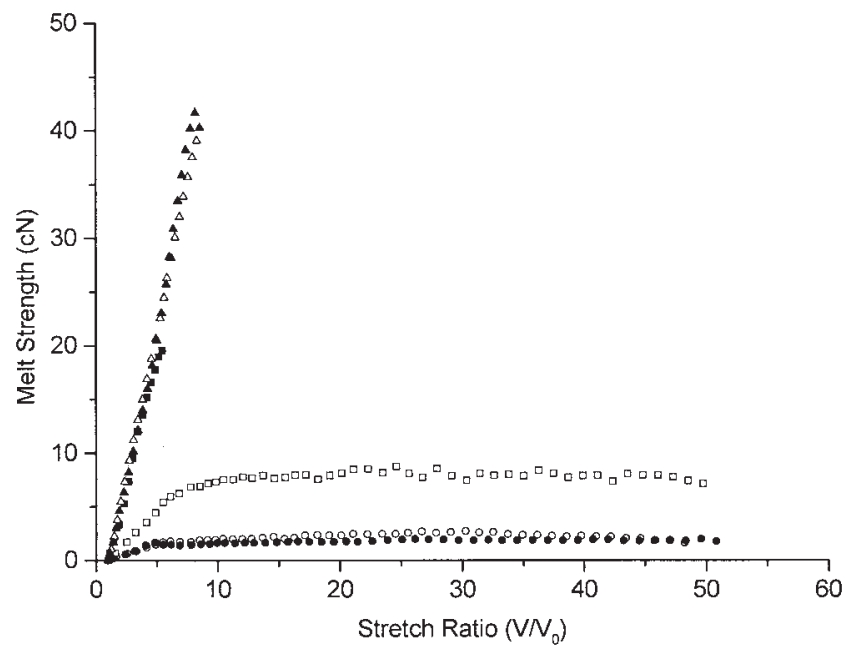

Figure 5 In-line melt strength measurements of modified PET. Effect of varying pentaerythritol concentration $(O)$

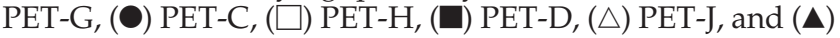
PET-F.

additive concentrations) while PET-D underwent fracture at a higher melt strength (similar to higher additive concentrations). The difference may represent a "crossing over" of predominating mechanisms-at low pentaerythritol concentrations, the hydroxy end groups of the polyester may play a more important role with the PMDA undergoing predominately chain extension, while at higher concentrations, the branching reactions of the pentaerythritol may predominate providing higher melt strengths and a more brittle fracture. This "crossing-over" occurred first at the 5:1 ratio compared to the $8: 1$ ratio and may be attributed to higher levels of available hydroxy groups.

Carboxyl groups determined via the titration method are provided in Table I. The PET control showed a significant increase in acid groups compared to the virgin material because of thermal and mechanical degradation during the extrusion process. There was a much smaller increase in the concentration of carboxyl end groups at $0.1 \mathrm{wt} \%$ PMDA (with and without pentaerythritol, PET- A, C, G) compared to the control. This could be due to the PMDA limiting hydrolysis reactions by preferential reaction with alcoholic moieties present in the extrusion process. At higher additions however, there was a marked increase in carboxy end groups, presumably because of contributions from the ring opening reactions of the PMDA as shown in Scheme 1, however, there was no observable trend with the composition of additives. End-group analyses were also performed using a newly developed NMR derivitization method. ${ }^{17}$ Figure 6 shows the ${ }^{1} \mathrm{H}$ NMR spectrum of the virgin PET derivatized with TAI. Derivatized terephthalate carboxyl and ethylene glycol hydroxy end groups appear at 10.3 and $8.5 \mathrm{ppm}$, respectively. The signal intensities observed are consistent with the end group concentration determined by titration. Similar analysis of extruded samples with lowest levels of PMDA (0.1\%) suggested little change in the concentration of end groups from that of extruded PET. However, analysis of the modified polyesters extruded with higher levels of PMDA addition showed a substantial decrease in the signals attributable to the both the TAI derivitized hydroxyl and carboxy chain ends. No new signals attributable to the TAI derivitized PMDA derived carboxyl groups of pentaerithritol derived hydroxyl groups were observed. It is presumed that the signals from the in-chain functionality are too broad to be observed. It is also possible that the rate reaction of TAI with in-chain functionality is slowed by steric hindrance or other factors. The selectivity in the NMR method is exploited here and indicates that the main source of carboxyl groups (as observed from the titration method) are those derived from the ring opening reaction of the PMDA with minimal contributions from the chain ends. The low concentration of end groups in the modified polyesters is consistent with long chain branching.

The rheological behavior was further studied post extrusion for some of the modified polyesters. Time sweep measurements were performed to determine if structural changes, e.g., additional chain extension and branching, occurred during the tests. Figure 7 shows little change in the complex viscosity up to 30 min, indicating no significant structural changes and that the modified polyesters were stable. Figure 8 shows the frequency dependence of $G^{\prime}$ and $G^{\prime \prime}$ for the

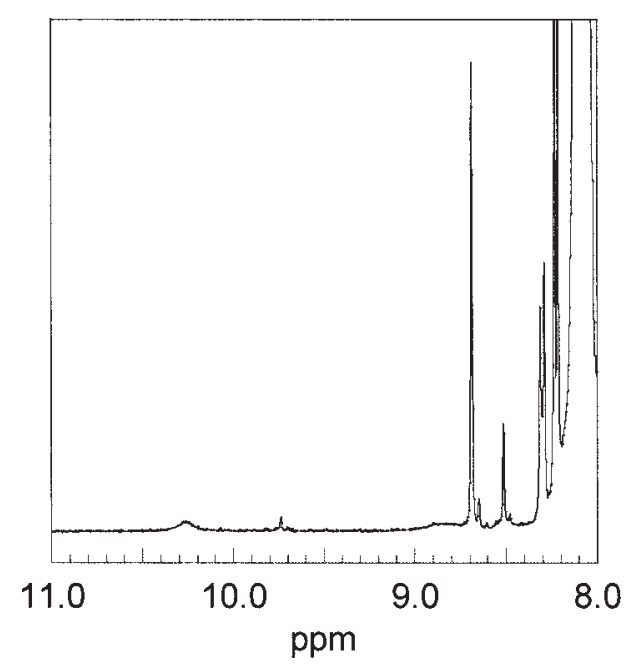

Figure 6 Portion (8-11 ppm) of the $400 \mathrm{MHz}$ NMR spectrum of PET (BK3180) following derivatization with TAI. Signals are assigned as follows: $10.25 \mathrm{ppm}$, $-\mathrm{C}(\mathrm{O})-\mathrm{O}-\mathrm{C}(\mathrm{O})-\mathrm{NH}-\mathrm{C}(\mathrm{O}) \mathrm{CCl}_{3}$ derived from $\mathrm{C}(\mathrm{O}) \mathrm{OH}$ end group and $8.5 \mathrm{ppm}-\mathrm{O}-\mathrm{C}(\mathrm{O})-\mathrm{NH}-\mathrm{C}(\mathrm{O}) \mathrm{CCl}_{3}$ derived from $-\mathrm{OH}$ end group. The signals at $8.7 \mathrm{ppm}$ and at $<8.3$ ppm are for terephthalate and isophthalate hydrogens. BK3180 contains $2.5 \mathrm{~mol} \%$ isophthalate. 
PET control and the modified polyesters. For all materials, the loss moduli G" were significantly greater than the storage moduli $G^{\prime}$ over the frequency range investigated. Examination of the low frequency region revealed the contribution of the storage modulus response to the total response (which is a measure of the melt elasticity), is lower for the PET control compared to the modified PET. This effect increased with the amount of PMDA and pentaerythritol (PET-H and PET-J, Fig. 8) and is attributed to increasing levels of branching.

\section{CONCLUSIONS}

Coaddition of PMDA with pentaerythritol was evaluated at different concentrations, for the modification of bottle grade PET in a reactive extrusion process. The extent of the modification was determined by measurements of the melt strength, apparent viscosity, loss modulus, and carboxyl group content. With increasing doses of PMDA alone, the modified polyesters exhibited higher viscosities at lower shear rates and experienced significant drops in the MFI. At low levels of coadded PMDA and pentaerythritol, there was a significant drop in the MFI and little improvement in the melt strength compared to the addition of PMDA alone. However, at higher concentrations of coaddition, there were marked improvements in melt strength and viscosity.

Post extrusion time sweep measurements of the complex viscosity revealed that the resultant modified polyesters were structurally stable in the the melt. The contribution of the storage modulus response to the total response was high for the modified polyesters

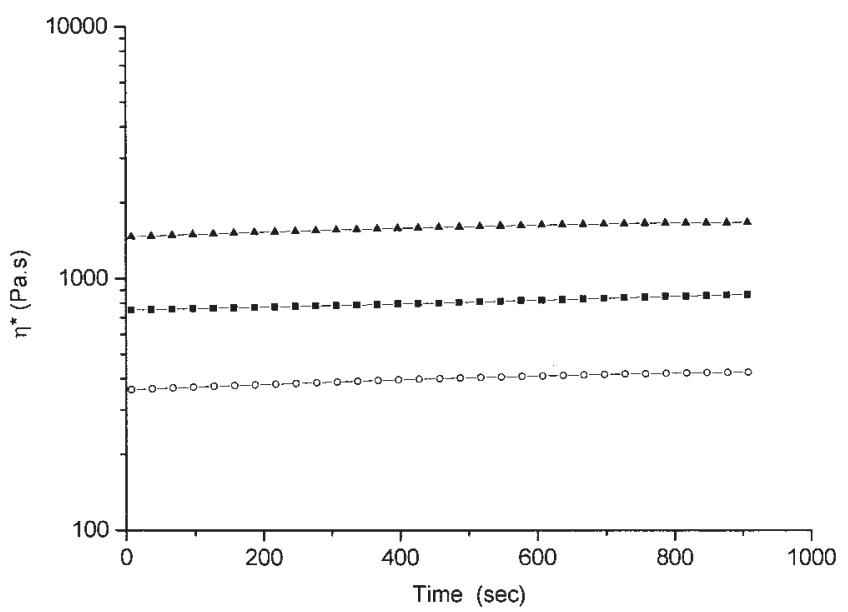

Figure 7 Post extrusion time sweeps of complex viscosity

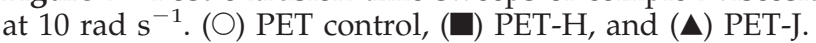

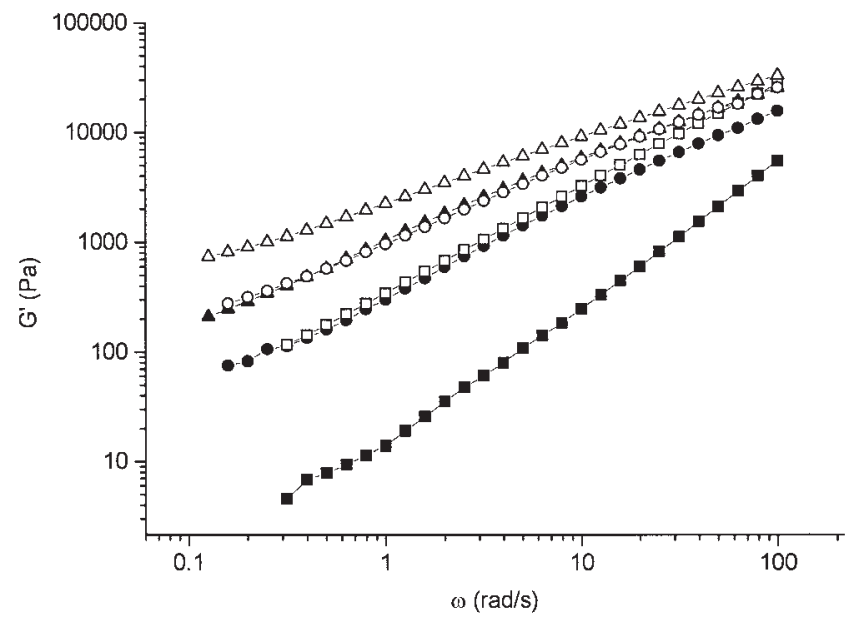

Figure 8 Loss modulus $G^{\prime}$ versus frequency of modified PET: ( $\square$ ) PET control G', ( $\square$ ) PET control G", ([cirof]) PET-H $\mathrm{G}^{\prime},(\bigcirc)$ PET-H G" $(\boldsymbol{\Delta})$ PET-J G', and $(\triangle)$ PET-J G".

and increased with the amount of PMDA and pentaerythritol, indicating increased levels of branching. These results are consistent with the formation of a hyperbranched polyester with long chain branches.

The authors wish to thank Kelvin Davies (VisyPak Australia) for helpful discussions.

\section{References}

1. Xanthos, M. In Handbook of Thermoplastic Polyesters; Fakirov, S., Ed.; Wiley-VCH: Weinheim, 2002; p 815.

2. Incarnato, L.; Scarfato, P.; Di Maio, L.; Acierno, D. Polymer 2000, $41,6825$.

3. Di Maio, L.; Incarnato, L.; Scarfato, P.; Acierno, D. Polym Rec 2001, 6, 77.

4. Awaja, F.; Daver, F.; Kosier E. Polym Eng Sci 2004, 44, 1579.

5. Khemani, K. C. In Proceedings of the 56th SPE ANTEC; Society of Plastics Engineers: Brookfield, CT, 1998; p 1934.

6. Xanthos, M.; Wan, C.; Dhavalikar, R.; Karayannidis, G. P.; Bikiaris, D. N. Polym Int 2004, 53, 1161.

7. Haralabakopoulos, A. A.; Tsiourvas, D. C.; Paleos, M. J Appl Polym Sci 1999, 71, 2121.

8. Xanthos, M.; Young, M. W.; Karayannidis, G. P.; Bikiaris, D. N. Polym Eng Sci 2001, 41, 643.

9. Dhavalikar, R.; Xanthos, M. J Appl Polym Sci 2002, 87, 643

10. Aharoni, S. M.; Masilamani, D. U.S. Pat. 4,568,720 (1986).

11. Inata, H.; Matsumura, S. J Appl Polym Sci 1986, 32, 5193.

12. Dhavalikar, R.; Yamaguchi, M.; Xanthos, M. J Polym Sci Part A: Polym Chem 2003, 41, 958.

13. Rotter, G. E.; Chiang, W.; Tsai, B. C.; Melquist, J. L.; Pauer, C. A.; Chen, S. Y. U.S. Pat. 5,536,793 (1996).

14. Van Diepen, G. J.; O'Shea, M. S.; Moad, G. U.S. Pat. 6,350,822 (2002).

15. Yilmazer, U.; Xanthos, M.; Gayram, G.; Tan, V. J Appl Polym Sci 2000, 75, 1371.

16. Khemani, K. C. In Polymeric Foams: Science and Technology; Khemani, K. C., Ed.; ACS: Washington, DC, 1997; p 54.

17. Donovan, A. R.; Moad, G. Polymer 2005, 45, 5005. 